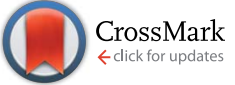

Cite this: Chem. Sci., 2016, 7, 5002

\title{
Visible light amination/Smiles cascade: access to phthalazine derivatives $\uparrow$
}

\author{
Etienne Brachet, ${ }^{\text {*a }}$ Leyre Marzo, $^{\mathrm{b}}$ Mohamed Selkti, ${ }^{\mathrm{c}}$ Burkhard König ${ }^{\mathrm{b}}$ \\ and Philippe Belmont ${ }^{\star a}$
}

We report the synthesis of various phthalazines via a new cascade reaction, initiated by visible light photocatalysis, involving a radical hydroamination reaction followed by a radical Smiles rearrangement. Phthalazine derivatives are obtained in high yields and from a broad scope readily accessible orthoalkynylsulfonohydrazone precursors. The mild photoredox conditions ensure an excellent functional group tolerance. Application of this strategy to a one-pot protocol starting from the corresponding carbonyl compounds, and subsequent functionalization allow the rapid synthesis of structurally diverse structures.

Received 9th March 2016

Accepted 6th May 2016

DOI: $10.1039 / \mathrm{c} 6 \mathrm{sc01095d}$

www.rsc.org/chemicalscience

alkynyl-phenylketones ${ }^{4}$ and Diels-Alder reactions. ${ }^{4 a, 5}$ These

\section{Introduction}

Since the early beginning of organic chemistry, the synthesis of nitrogen-containing heterocycles constantly attracted interest from the chemistry community, due to their ubiquitous presence in natural products. ${ }^{1}$ Until now, despite many synthetic efforts, phthalazine structures have been less explored and therefore synthetic methods are still desirable. Moreover, these heterocycles are found in many important biological relevant compounds possessing properties, such as antibacterial ${ }^{2}$ or antitumor $^{3}$ agents (Fig. 1).

Current strategies for the synthesis of these heterocycles are limited to the use of hydrazine on diaryldiketones or ortho
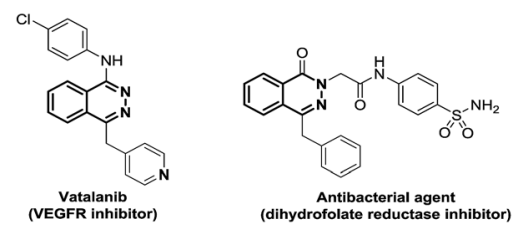

Fig. 1 Phthalazines bioactive compounds.

\footnotetext{
aniversité Sorbonne Paris Cité (USPC), Université Paris Descartes, Faculté de Pharmacie de Paris, UMR CNRS 8638 (COMETE), 4 avenue de l'Observatoire, 75006 Paris, France. E-mail: etienne.brachet@parisdescartes.fr; philippe.belmont@ parisdescartes.fr

${ }^{b}$ University of Regensburg Faculty of Chemistry and Pharmacy, Institute of Organic Chemistry, Universitätsstraße 31, 93053 Regensburg, Germany

'Université Sorbonne Paris Cité (USPC), Université Paris Descartes, Faculté de Pharmacie de Paris, UMR CNRS 8015 (LCRB), 4 avenue de l'Observatoire, 75006 Paris, France

$\dagger$ Electronic supplementary information (ESI) available. CCDC 1450316. For ESI and crystallographic data in CIF or other electronic format see DOI: 10.1039/c6sc01095d
} reactions require sometimes harsh reaction conditions and/or use toxic hydrazine reagents, limiting the access to phthalazine structures. ${ }^{4,5}$ Therefore, looking for a general strategy to build phthalazine derivatives is still highly requested. We were thus interested in developing a milder and general protocol focusing on the formation of the $\mathrm{C}-\mathrm{N}$ bond via a photoredox strategy. Carbon-nitrogen bonds are ubiquitous and essential in countless important organic compounds. ${ }^{1}$ Thus, chemists have developed a plethora of strategies to synthesize $\mathrm{C}-\mathrm{N}$ bonds leading to diversified structures. ${ }^{6,7}$ Tremendous improvements were made over the last decades especially thanks to transition metal catalysis, such as Buchwald-Hartwig amination ${ }^{6}$ or oxidative amination reactions. ${ }^{7}$ Nevertheless, $\mathrm{C}-\mathrm{N}$ bond formation reactions remain of great interest, particularly in developing more general, milder and ecofriendly conditions.

In this context, carbo-amination and hydro-amination reactions, especially via radical mechanisms, are currently under investigation. ${ }^{8}$ By taking advantage of photocatalyzed reactions, ${ }^{9}$ we propose an unprecedented photo-induced radical cascade reaction combining a hydro-amination reaction step followed by a Smiles rearrangement.

The reported examples of $\mathrm{C}-\mathrm{N}$ bond formation using photoredox catalysis mainly differ in nitrogen radical precursors (hydrazone, azide, $N$-acyloxyphthalimides, $N$-oxyl sulfonylcarbamates...). ${ }^{10}$ Among them, hydrazone precursors were initially converted into radicals using stoichiometric quantities of TEMPO ${ }^{11}$ or azodicarboxylate reagents ${ }^{12}$ yielding pyrazoline derivatives, via an intramolecular 5-exo-trig cyclisation process. In these cases, the heterocyclic products were obtained predominantly as adducts with the radical initiator ${ }^{13}$ (Scheme 1A). Last year, Chen, Xiao and coworkers were able to replace stoichiometric oxidation with catalytic photo-oxidation, using visible light, leading to pyrazolines, thanks to the base- 

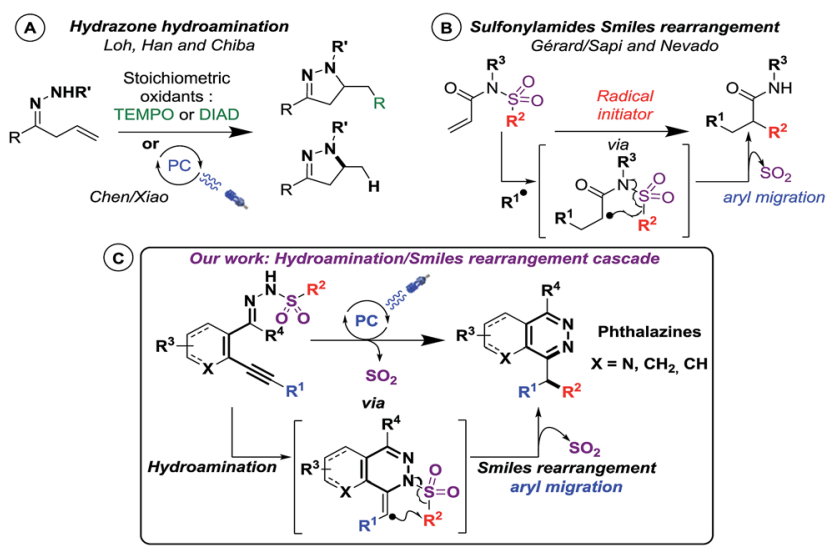

Scheme 1 State of art in radical hydro- and oxo-amination reactions and in the radical Smiles rearrangement ( $A$ and $B$ ); our photocatalyzed cascade (C).

mediated photocatalytic conversion of the $\mathrm{N}-\mathrm{H}$ bond into an $\mathrm{N}-$ centered radical. ${ }^{14}$ In both cases, the nitrogen radical, generated on a hydrazone precursor, makes an intramolecular attack on an alkenyl residue (Scheme 1A). It is noteworthy that all reported photo-induced cyclization reactions of nitrogen-based radicals on unsaturated moieties happen on alkenyl residues. ${ }^{9 f}$ Intriguingly, cyclization reactions of nitrogen-based radicals on alkynyl residues have never been investigated under visible light catalysis. ${ }^{9 f, 10 g-j}$ Therefore, our findings are of particular interest since we designed new alkynyl-substituted arylsulfonohydrazone precursors (Scheme 1C) involved in intramolecular photo-induced hydro-amination to alkynes. To our delight, we were thrilled to isolate benzhydryl-substituted phthalazine structures through a subsequent radical Smiles rearrangement. Indeed, only a few recent examples of radical Smiles rearrangements (aryl migration ${ }^{15}$ ) from Gérard/Sapi ${ }^{16}$ and Nevado, ${ }^{17}$ using sulfonylamides precursors, demonstrated that this process could happen in a radical fashion (Scheme 1B), but no report included an arylsulfonohydrazone scaffold. Therefore, we describe here the behavior of novel phenylsulfonohydrazone moieties in an unprecedented photo-induced reaction cascade. ${ }^{18}$ We found that they were able to undergo an intramolecular hydroamination reaction followed by a Smiles rearrangement, providing a new strategy to build phthalazine derivatives, under visible light catalysis (Scheme 1C).

\section{Results and discussion}

We started our investigation on a model substrate, $N^{\prime}$-(2-(phenylethynyl)benzylidene)benzenesulfonohydrazone 1a, easily prepared from the corresponding carbony ${ }^{19 a}$ and sulfonohydrazide moieties (Table 2). We optimized the reaction conditions (see ESI $†$ for full details) modifying the nature of the base, of the solvent, of the photocatalyst and the crucial presence of a drying agent. Starting from reaction conditions using $\mathrm{Ru}(\mathrm{bpy})_{3} \mathrm{Cl}_{2} \cdot 6 \mathrm{H}_{2} \mathrm{O}$ as the photocatalyst, and $\mathrm{NaOH}$ as the base in $\mathrm{CHCl}_{3}$, we were pleased to isolate the desired product 2a with an encouraging yield of $25 \%$ (Table 1 , entry 1). The X-ray
Table 1 Optimization of the reaction conditions

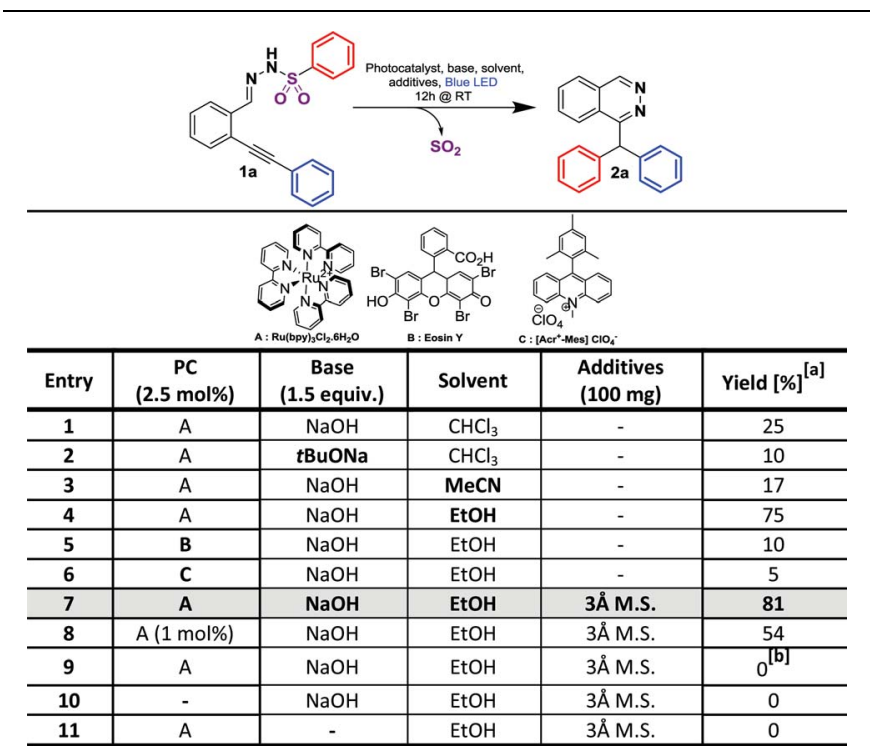

${ }^{a}$ Isolated yields. ${ }^{b}$ Without light.

analysis of $2 \mathbf{a}$ (Table 2) unambiguously confirmed the structure. Changing the base from $\mathrm{NaOH}$ to $t \mathrm{BuONa}$ leads to a lower $10 \%$ yield (entry 2). Investigation on the nature of the solvent (Entries 3 and 4) allowed us to increase the isolated yield from $25 \%$ to $75 \%$ with EtOH (entry 4). The influence of the photocatalyst was then evaluated with Eosin $\mathrm{Y}^{9}$ and Fukuzumi's catalyst. ${ }^{9}$ However, the reaction was inefficient in both cases, leading to a $10 \%$ or $5 \%$ product yield, respectively, for entries 5 and 6 . Additives were then screened and we were pleased to find that, with the use of $3 \AA$ molecular sieves, we were able to avoid the formation of a side product, thus improving the yield of the desired product 2a to $81 \%$ (see ESI $\dagger$ ). Decreasing the amount of the ruthenium catalyst from $2.5 \mathrm{~mol} \%$ to $1 \mathrm{~mol} \%$ led to a lower yield of $54 \%$ (entry 8). The presence of the photocatalyst, a base and light proved to be crucial for the reaction since the lack of one of them prevented the formation of product $\mathbf{2 a}$ (entries 911). Finally, the optimized reaction conditions are: $2.5 \mathrm{~mol} \%$ of $\mathrm{Ru}(\mathrm{bpy})_{3} \mathrm{Cl}_{2} \cdot 6 \mathrm{H}_{2} \mathrm{O}, 1.5$ equivalents of $\mathrm{NaOH}$ and $100 \mathrm{mg}$ of $3 \AA$ molecular sieves in EtOH $(0.08 \mathrm{M})$ under blue light irradiation $(\sim 450 \mathrm{~nm})$. With these conditions in hand, we explored the reaction scope. At first, we examined the impact of alkyne substitution by evaluating various aryls with ortho, meta or para substituents, exhibiting electron-donating or electron-withdrawing properties (1b-h, Fig. 2 and $\mathbf{2 b}-\mathbf{h}$, Table 2). Electrondonating groups are well tolerated; para-methyl or metamethoxy substituted derivatives $\mathbf{2 b}$ and $2 \mathbf{c}$ provided good product yields, 71 and $79 \%$, respectively. 3,4,5-Trimethoxybenzene derivative 1d gave the expected product $2 \mathrm{~d}$ in $60 \%$ yield (Table 2). Electron-withdrawing groups are also well tolerated, producing para- and ortho-fluoro or para-trifluoromethyl derivatives $\mathbf{2 g} / \mathbf{2} \mathbf{h} / \mathbf{2 f}$ with moderate to good isolated yields of $83 \%, 61 \%$ or $55 \%$, respectively. However, paranitro derivative $1 \mathrm{e}$ was unreactive under these conditions due to 
Table 2 Scope of the reaction ${ }^{a}$

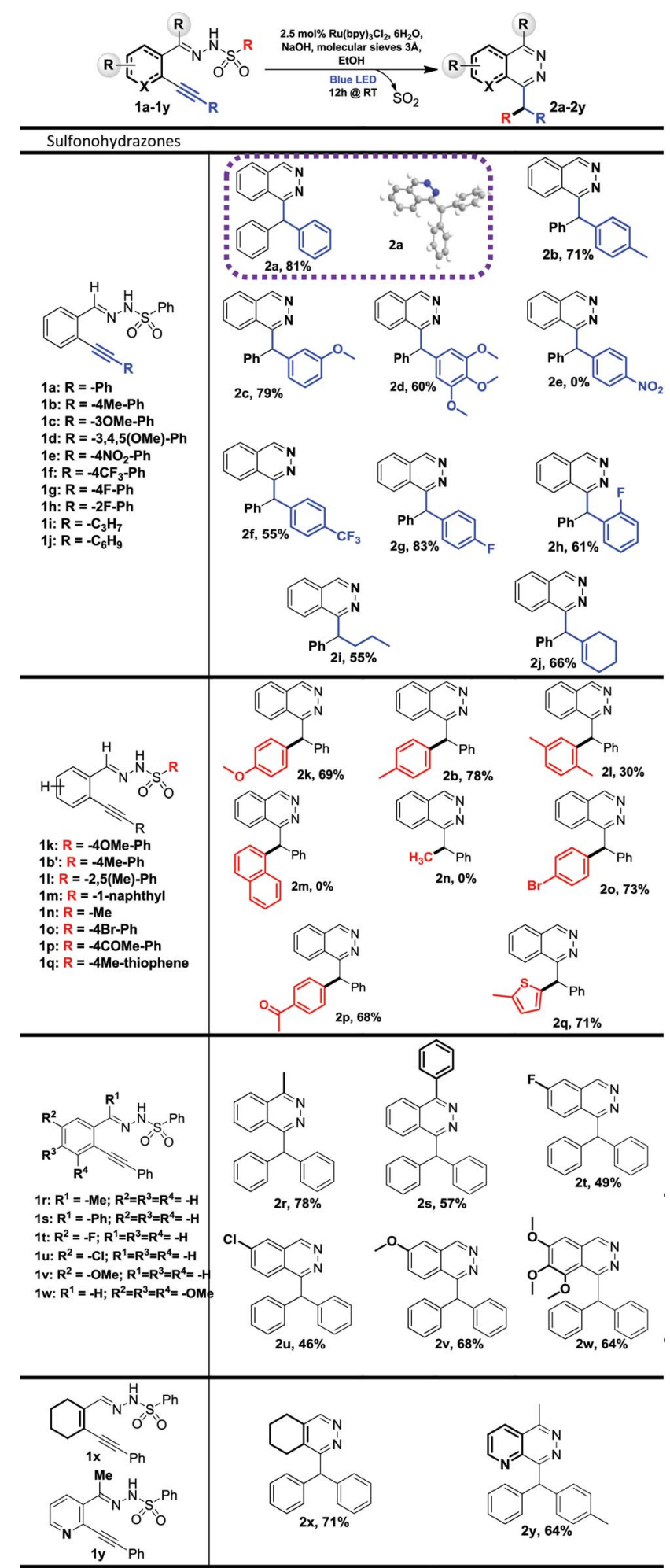

${ }^{a}$ Reaction conditions: 1a-y (0.15 mmol, 1 eq.), 3 А M.S. (100 mg), Rubpy ${ }_{3} \mathrm{Cl}_{2} \cdot 6 \mathrm{H}_{2} \mathrm{O}(3.5 \mu \mathrm{mol}, 2.5 \mathrm{~mol} \%)$ and $\mathrm{NaOH}(0.225 \mathrm{mmol}$, 1.5 eq.) in dry EtOH $(0.08 \mathrm{M})$ was irradiated for $12 \mathrm{~h}$ under blue light $(450 \mathrm{~nm})$ at $20^{\circ} \mathrm{C}$. low solubility in ethanol. Cyclohexenyl derivative $\mathbf{1 j}$ reacted chemoselectively, yielding $\mathbf{2 j}$ in $66 \%$ yield (Table 2 ). Starting from pentyne derivative $\mathbf{1 i}$, we obtained product $\mathbf{2 i}$ in a moderate $55 \%$ yield.

Then, we investigated the reaction scope for the sulfonyl part $\left(\mathbf{1} \mathbf{b}^{\prime}, \mathbf{1 k}-\mathbf{r}\right.$, Fig. 2) of the starting materials, thus modifying the migrating moiety.

Derivatives bearing electron donating-groups, such as paramethoxy or para-tolyl on the phenyl ring of sulfonohydrazone, gave the desired products $2 \mathbf{k}$ and $2 \mathbf{b}$ in $69 \%$ and $78 \%$ yields, respectively (Table 2). Steric congestion is detrimental to the reaction: xylene substitution provided the desired product $\mathbf{2 l}$ in only $30 \%$ yield; 1 -naphthalene substitution $(\mathbf{1 m})$ is unreactive under these conditions and the starting material is almost fully recovered. Bromo-substituted phenylsulfonohydrazone reacted nicely to 20 in $73 \%$ yield; this derivative could be further functionalized using cross-coupling reactions. Derivatives bearing electron-withdrawing groups, such as para-acetyl on the phenylsulfonohydrazone moiety, yield product 2 p in $68 \%$ yield. Alkyl-substituted sulfonohydrazones are not tolerated under our conditions. Indeed methylsulfonohydrazone 1n (or benzylsulfonohydrazone, data not shown) did not yield any reaction product. Finally, heteroarene-derived sulfonohydrazone, 2-methylthiophene 1q, was successfully transferred giving the desired product $\mathbf{2 q}$ in $\mathbf{7 1} \%$ yield. Differently substituted benzaldehyde units on the carbamoyl or aromatic part were synthesized and evaluated in the reaction (1r-y, Table 2). Thus, 1-substituted phthalazines became accessible via our new process and compounds $2 \mathbf{r}$ and $2 \mathbf{s}$ were obtained with yields of $78 \%$ and $57 \%$, respectively. Then, the aromatic part was substituted by electron-donating or -withdrawing groups and we isolated products (2t-w) in moderate to good yields (46$68 \%$ ). Finally, we applied the method to the synthesis of other heterocycles and obtained pyridazine $2 \mathbf{x}$ and pyridopyridazine $2 y$ in $71 \%$ and $64 \%$ yield, respectively. The reaction was also attempted in a sequential one-pot process. This one-pot strategy was successfully applied to the synthesis of four compounds with yields ranging from 61 to $77 \%$, which are similar compared to the two-steps procedure for compounds $\mathbf{2 a}, \mathbf{2 b}$ and $\mathbf{2 k}$, (Tables 2 and 3 ) and one new disubstituted analog $\mathbf{2 z}$. The one-

Table 3 One-pot two-step synthesis of benzhydrylphthalazines ${ }^{a}$

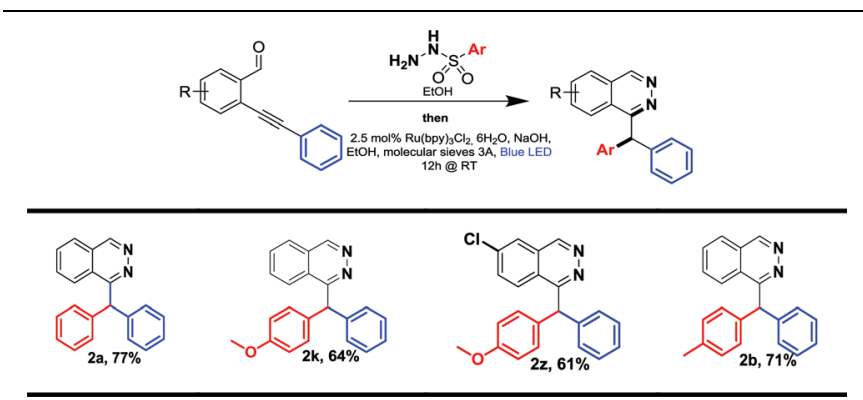

${ }^{a}$ Reaction conditions: benzaldehyde (0.15 mmol, 1 eq. $)$ and sulfonylhydrazine $(0.15 \mathrm{mmol}, 1 \mathrm{eq}$.) were mixed at room temperature in EtOH $(1 \mathrm{~mL})$ for 1 hour, then we followed our optimized conditions. 


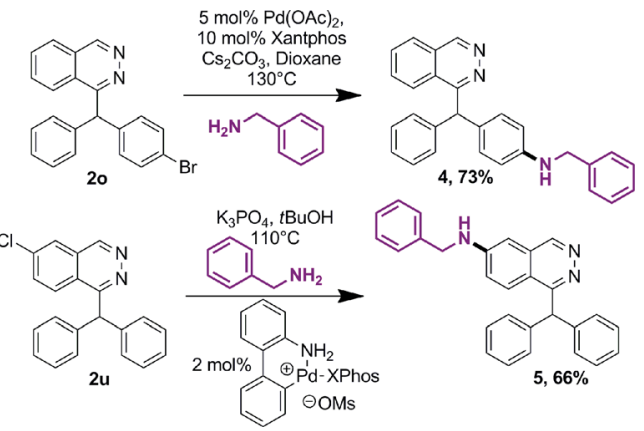

Scheme 2 Functionalization of halogenobenzhydrylphthalazines.

pot process could be particularly attractive for the synthesis of phthalazine or pyridazine compound libraries (Table 3).

Further functionalization of phthalazine derivatives is possible, since the presence of a halogen atom is compatible with our cascade process, either on a phthalazine substituent $(2 \mathbf{2}$, Table 3$)$ or directly on the phthalazine core $(\mathbf{2 u})$. As an example, the Buchwald-Hartwig cross-coupling reaction of compounds $2 \mathbf{o}$ and $2 \mathbf{u}$ with benzylamine provided products 4 and 5 in $73 \%$ and $66 \%$ yield, respectively (Scheme 2). ${ }^{19}$

\section{Mechanistic study}

A proposed mechanism based on the observations of several control experiments and measurements is depicted in Scheme 3. The reaction in $\mathrm{MeOH}-\mathrm{d} 4$ gave deuterated product 2aa in $68 \%$ yield with more than $85 \%$ incorporation of deuterium, confirming that the solvent is the proton source. Cyclic voltammetry measurements suggest that only a deprotonated sulfonohydrazone II $\left(E_{\text {III/II }}=0.54 \mathrm{eV} v s\right.$. SCE $)$ can be photo-oxidized by the excited ruthenium-based photocatalyst $\left(E_{\mathrm{RuII}} * / \mathrm{RuI}=0.77 \mathrm{eV} v s\right.$. SCE $)$, confirmed by further fluorescence experiments (see $\mathrm{ESI} \uparrow$ for data). Then, the $\mathrm{N}$-centered radical III

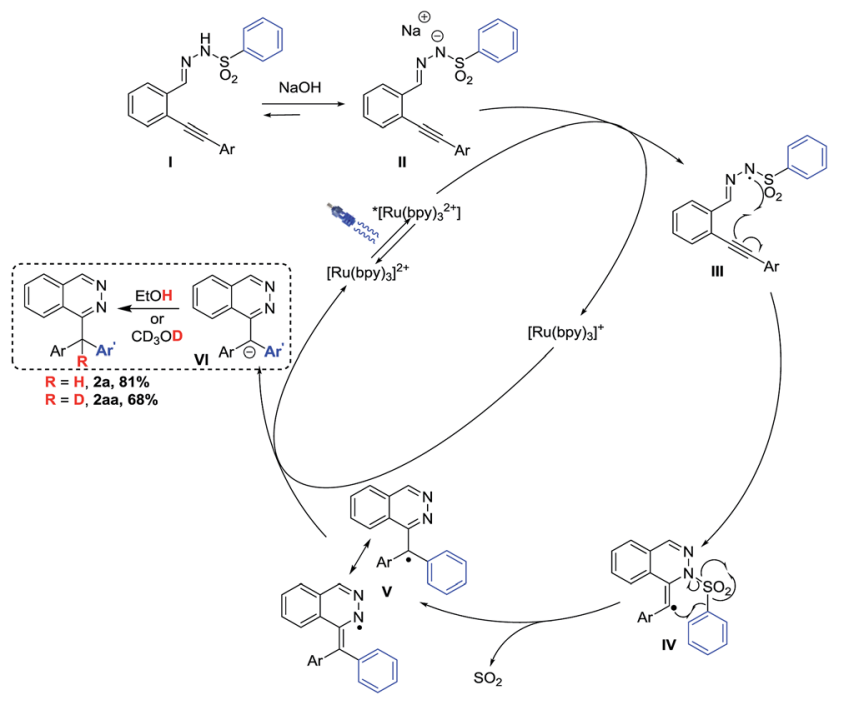

Scheme 3 Proposed mechanism. may add to the triple bond and the loss of sulfur dioxide in intermediate IV yields the phthalazine radical structure $\mathbf{V}$ (C-centered and $\mathrm{N}$-centered radical species in equilibrium). The reduction of intermediate $\mathbf{V}$ through the regeneration of the catalyst yields anion VI, which can be protonated or deuterated by the solvent (2a, 2aa). The quantum yield of the reaction was determined to be $\Phi=0.33$ indicating that the mechanism does not contain significant radical chain pathways. ${ }^{20}$

\section{Conclusions}

In summary, we have developed a new photoredox cascade process combining a hydroamination reaction followed by a Smiles rearrangement. This unprecedented transformation provides an efficient access to highly diversified benzhydrylphthalazine structures. Moreover, mechanistic investigations confirmed the radical pathway displayed in our proposed mechanism. Halogen substituents are tolerated, allowing, through subsequent cross-coupling reaction, further functionalization of the phthalazines. The in situ preparation of the sulfonohydrazones from the corresponding carbonyl substrates allows a one-pot procedure. We currently investigate further applications of the photoredox Smiles reaction in our laboratory.

\section{Acknowledgements}

EB and PB are thankful for the CNRS/INCa ATIP fellowship and research encouragement from "Université Paris Descartes" and "Faculté de Pharmacie de Paris". We are grateful for the mass spectrometry facilities at "Faculté de Pharmacie de Paris" (P. Leproux). Special thanks for helpful scientific discussions are extended to the team Heterocycles and Peptides (UMR 8638). LM and BK thank the German Science Foundation (GRK 1626) for the financial support of our work.

\section{Notes and references}

1 (a) Heterocycles in Natural Product Synthesis, ed. K. C. Majumdar and S. K. Chattopadhyay, Wiley, Hoboken, NJ, 2012; (b) D. A. Horton, G. T. Bourne and M. L. Smythe, Chem. Rev., 2003, 103, 893; (c) A. Deiters and S. F. Martin, Chem. Rev., 2004, 104, 2199; (d) F. R. de Sá Alves, E. J. Barreiro and C. A. Fraga, Mini-Rev. Med. Chem., 2009, 9, 782; (e) A. Brancale and R. Silvestri, Med. Res. Rev., 2007, 27, 209; (f) G. Zeni and R. Larock, Chem. Rev., 2004, 104, 2285.

2 H. S. Ibrahim, W. M. Eldehna, H. A. Abdel-Aziz, M. M. Elaasser and M. M. Abdel-Aziz, Eur. J. Med. Chem., 2014, 85, 480.

3 E. N. Scott, G. Meinhardt, C. Jacques, D. Laurent and A. L. Thomas, Expert Opin. Invest. Drugs, 2007, 16, 367.

4 (a) M. Asif, Curr. Med. Chem., 2012, 19, 2984; (b) C. Dong, Z. Liao, X. Xu and H. Zhou, J. Heterocycl. Chem., 2014, 51, 1282; (c) J. Munína, L. Santanab, E. Uriarteb, F. Borgesc and E. Quezada, Tetrahedron Lett., 2015, 56, 828; (d) Y. Maki, T. Furuta and M. Suzuki, J. Chem. Soc., Perkin 
Trans. 1, 1979, 553; (e) G. Heinisch and T. Huber, J. Heterocycl. Chem., 2009, 26, 1787.

5 S.-E. Suh, S. A. Barros and D. M. Chenoweth, Chem. Sci., 2015, 6, 5128-5132.

6 (a) D. S. Surry and S. L. Buchwald, Chem. Sci., 2010, 1, 13; (b) D. S. Surry and S. L. Buchwald, Chem. Sci., 2011, 2, 27; (c) J. F. Hartwig, Acc. Chem. Res., 2008, 41, 1534; (d) G. Evano, N. Blanchard and M. Toumi, Chem. Rev., 2008, 108, 3054.

7 (a) M. L. Louillat and F. W. Patureau, Chem. Soc. Rev., 2014, 43, 901; (b) J. L. Jeffrey and R. Sarpong, Chem. Sci., 2013, 4, 4092; (c) S. H. Cho, J. Y. Kim, J. Kwak and S. Chang, Chem. Soc. Rev., 2011, 40, 5068; (d) F. Collet, C. Lescot and P. Dauban, Chem. Soc. Rev., 2011, 40, 1926.

8 (a) M. T. Pirnot, Y.-M. Wang and S. L. Buchwald, Angew. Chem., Int. Ed., 2016, 55, 48; (b) M. Villa and A. Jacobi von Wangelin, Angew. Chem., Int. Ed., 2015, 54, 11906.

9 Selected reviews on photocatalysis: (a) J. Xuan and W. J. Xiao, Angew. Chem., Int. Ed., 2012, 51, 6828; (b) C. K. Prier, D. A. Rankic and D. W. C. MacMillan, Chem. Rev., 2013, 113, 5322; (c) M. N. Hopkinson, B. Sahoo, J.-L. Li and F. Glorius, Chem. - Eur. J., 2014, 20, 3874; (d) D. A. Nicewicz and T. M. Nguyen, ACS Catal., 2014, 4, 355; (e) D. P. Hari and B. König, Angew. Chem., Int. Ed., 2013, 52, 4734; $(f)$ J.-R. Chen, X.-Q. Hu, L.-Q. Lu and W.-J. Xiao, Chem. Soc. Rev., 2016, 45, 2044-2056; $(g)$ J.-R. Chen, X.-Y. Yu and W.-J. Xiao, Synthesis, 2014, 47, 604.

10 (a) E. Brachet, T. Ghosh, I. Ghosh and B. König, Chem. Sci., 2015, 6, 987-992; (b) D. C. Miller, G. J. Choi, H. S. Orbe and R. R. Knowles, J. Am. Chem. Soc., 2015, 137, 13492; (c) N. A. Romero, K. A. Margrey, N. E. Tay and D. A. Nicewicz, Science, 2015, 349, 1326; (d) Q. Qin and S. Yu, Org. Lett., 2015, 17, 1894; (e) L. J. Allen, P. J. Cabrera, M. Lee and M. S. Sanford, J. Am. Chem. Soc., 2014, 136, 5607; (f) G. Cecere, C. M. König, J. L. Alleva and D. W. C. MacMillan, J. Am. Chem. Soc., 2013, 135, 11521; (g) J.-R. Chen, X.-Y. Yu and W.-J. Xiao, Synthesis, 2014, 47, 604. Nevertheless $\mathrm{N}$-centered radicals addition on alkynes have been already reported using classical radical initiator: (h) U. Wille, G. Heuger and C. Jargstorff, J. Org. Chem.,
2008, 73, 1413; (i) G. Zheng, Y. Li, J. Han, T. Xiong and Q. Zhang, Nat. Commun., 2015, 6, 7011; (j) U. Wille, Chem. Rev., 2013, 113, 813.

11 (a) X.-Y. Duan, N.-N. Zhou, R. Fang, X.-L. Yang, W. Yu and B. Han, Angew. Chem., Int. Ed., 2014, 53, 3158; (b) X.-Y. Duan, X. L. Yang, R. Fang, X. X. Peng, W. Yu and B. Han, J. Org. Chem., 2013, 78, 10692.

12 M. K. Zhu, Y. C. Chen and T. P. Loh, Chem. - Eur. J., 2013, 19, 5250.

13 Only one paper reported a radical ring closing of hydrazones on alkenes leading to pyrazolines without trapping of the radical initiator used: X. Zhu, Y.-F. Wang, W. Ren, F.-L. Zhang and S. Chiba, Org. Lett., 2013, 15, 3214.

14 X.-Q. Hu, J.-R. Chen, Q. Wei, F.-L. Liu, Q.-H. Deng, A. M. Beauchemin and W.-J. Xiao, Angew. Chem., Int. Ed., 2014, 53, 12163.

15 (a) A. Gheorghe, B. Quiclet-Sire, X. Vila and S. Z. Zard, Org. Lett., 2005, 7, 1653; (b) A. Studer and M. Bossart, Tetrahedron, 2001, 57, 9649; (c) T. J. Snape, Chem. Soc. Rev., 2008, 37, 2452.

16 M. Pudlo, I. Allart-Simon, B. Tinant, S. Gérard and J. Sapi, Chem. Commun., 2012, 48, 2442.

17 (a) W. Kong, M. Casimiro, E. Merino and C. Nevado, J. Am. Chem. Soc., 2013, 135, 14480; (b) W. Kong, N. Fuentes, A. Garcia-Dominguez, E. Merino and C. Nevado, Angew. Chem., Int. Ed., 2015, 54, 2487.

18 The photo-induced Smiles rearrangement has been recently reported exclusively on difluorobromo sulfonate substrates needed for the generation of the gem-difluoro radical. J. J. Douglas, H. Albright, M. J. Sevrin, K. P. Cole and C. R. J. Stephenson, Angew. Chem., Int. Ed., 2015, 54, 14898. 19 (a) G. Mariaule, G. Newsome, P. Y. Toullec, P. Belmont and V. Michelet, Org. Lett., 2014, 16, 4570; (b) R. Martin and S. L. Buchwald, Acc. Chem. Res., 2008, 41, 1461; (c) E. Brachet, J.-F. Peyrat, J.-D. Brion, S. Messaoudi and M. Alami, Org. Biomol. Chem., 2013, 11, 3808; (d) N. C. Bruno and S. L. Buchwald, Org. Lett., 2013, 15, 2876. 20 M. A. Cismesia and T. P. Yoon, Chem. Sci., 2015, 6, 5426. 